\title{
The management of chest tubes after pulmonary lobectomy-driven by dogma or by science?
}

\author{
Hiran C. Fernando \\ Department of Surgery, Inova Fairfax Medical Campus, Falls Church, VA, USA \\ Correspondence to: Hiran C. Fernando, MBBS, FRCS, FRCSEd. Department of Surgery, Inova Fairfax Medical Campus, Falls Church, VA, USA. \\ Email: Hiran.Fernando@inova.org. \\ Comment on: Gao S, Zhang Z, Aragón J, et al. The Society for Translational Medicine: clinical practice guidelines for the postoperative management \\ of chest tube for patients undergoing lobectomy. J Thorac Dis 2017;9:3255-64.
}

Submitted Oct 10, 2018. Accepted for publication Oct 12, 2018.

doi: $10.21037 /$ jtd.2018.10.47

View this article at: http://dx.doi.org/10.21037/jtd.2018.10.47

The management of chest-tubes after lobectomy varies widely, with differing practices between centers and even between physicians practicing within the same center. It is one of those areas in thoracic surgery that has largely been driven by experiences during training, and to a greater extent by surgical dogma rather than based on the results of randomized trials. In 2011 the European Society of Thoracic Surgeons (ESTS), American Association for Thoracic Surgery (AATS), Society of Thoracic Surgeons (STS) and General Thoracic Surgical Club (GTSC) published a consensus paper addressing some of the inconsistencies regarding the management of chesttubes (1). However, rather than providing evidence-based statements, the task force involved in that effort, provided a standardized set of definitions and nomenclature to help future investigators and clinicians in this area.

Now 7 years later, Gao et al. have developed a practice guideline based on a systemic review of the literature on this topic (2). Although initiated by the Society of Translational Medicine and the Chinese Thoracic Society for Thoracic and Cardiovascular Surgery, the authors also include several international experts. It is noteworthy that despite the significant efforts of this multi-national group, many of the recommendations are $2 \mathrm{a}-2 \mathrm{c}$ attesting to a paucity of well-designed randomized trials regarding chest-tube management. For instance, a $2 \mathrm{~b}$ recommendation was made that chest-tubes can be removed safely with daily pleural fluid of up to $450 \mathrm{cc}$. However in one study that allowed volumes to $450 \mathrm{cc}, 20 \%$ of patients required thoracentesis for hydrothorax (3). A well designed study looking at larger pleural fluid drainages, with volumes acceptable to most surgeons would help answer this question further.

An area of great interest is the incorporation of electronic drainage systems into clinical practice. It is noteworthy that the strongest recommendation that Gao et al. made was the $1 \mathrm{~b}$ recommendation favoring the use of electronic drainage systems for patients undergoing lobectomy. In fact, this was the only "strong" recommendation in their guideline. Most likely this was the based on the fact that seven randomized trials used electronic systems, of which five were found to be significantly associated with reduced chest-tube duration and hospital stay. Despite these recommendations most centers do not routinely use electronic drainage systems. In part this will be related to costs and further studies are needed to evaluate this further. Another consideration is that not all systems are the same. The challenge for thoracic surgeons interested in incorporating this technology will be deciding which system to use, and how to convince their hospital technology assessment committees to purchase these. However, the current consensus would suggest that these electronic drainage systems do help to reduce clinical variability in chest-tube management among members of a patient's care-team.

In summary, this guideline is a useful resource to thoracic surgeons, that is helpful to understanding the current limitations on the data supporting the routine, but widely different practices of chest-tube management.

\section{Acknowledgements}

None. 


\section{Footnote}

Conflicts of Interest: The author has no conflicts of interest to declare.

\section{References}

1. Brunelli A, Beretta E, Cassivi SD, et al. Consensus definitions to promote an evidence-based approach to management of the pleural space. A collaborative proposal by ESTS, AATS, STS, and GTSC. Eur J Cardiothorac

Cite this article as: Fernando HC. The management of chest tubes after pulmonary lobectomy-driven by dogma or by science? J Thorac Dis 2018;10(11):5968-5969. doi: 10.21037/ jtd.2018.10.47
Surg 2011;40:291-7.

2. Gao S, Zhang Z, Aragón J, et al. The Society for Translational Medicine: clinical practice guidelines for the postoperative management of chest tube for patients undergoing lobectomy. J Thorac Dis 2017;9:3255-64.

3. Xie HY, Xu K, Tang JX, et al. A prospective randomized controlled trial deems a drainage of $300 \mathrm{~mL} /$ day safe before removal of the last chest drain after video-assisted thoracoscopic surgery lobectomy. Interact Cardiovasc Thorac Surg 2015;21:200-5. 